\title{
Micrococcal nuclease (endonuclease) digestion causes apoptosis and mitotic catastrophe with interphase chromosome condensation in human Chang liver cells
}

\author{
Lei Yin ${ }^{1}$ and Kwok-Hung Sit ${ }^{1,2}$ \\ ${ }^{1}$ Anatomy Department, Faculty of Medicine, National University of Singapore, \\ Kent Ridge, Singapore, Singapore 119260 \\ 2 corresponding author
}

Received 5.11.96; revised 24.4.97; accepted 30.7.97

Edited by J. Cidlowski

\begin{abstract}
Endonuclease activation causing genomic degradation is a pervasive hallmark of apoptosis and a suggested precipitating or commitment step in the suicidal process. Directly applied endonuclease activity has produced apoptotic-like effects in isolated nuclei, but not yet shown as an initiating apoptogen in whole cells. Mechanistically genomic damage inflicted by a variety of DNA-damaging agents is also known to produce mitotic catastrophe condensations characterizing cell cycle derangement. Morphological and molecular similarities between apoptosis and mitotic catastrophe have been noted, but their conjoint expressions from directly applied endonuclease activity has also not been shown. We show here micrococcal nuclease (MNase) initiating apoptosis in human Chang liver cells which expressed both apoptotic and mitotic catastrophe condensations. Genomic profiling showed (a) the two stage apoptotic sequence of large $(50 \mathrm{~kb})$ and small (200 bp) fragment cleavage demonstrated by pulse field and normal gel electrophoresis, respectively; (b) the sub-G1 'apoptotic peak' with shrunken cells from flow cytometric evaluation of PI-DNA binding and laser forward scattering, (c) 3 ' OH termini typical of apoptotic DNA fragments labelled by terminal deoxynucleotidyl transferase (TdT)-mediated fluorescence tagging especially in the shrunken cells, and (d) positive comet assay of the apoptotic genome. Nuclear shrinkage evaluated by confocal image analysis was consistent with the apoptotic response, as was $\mathrm{Zn}^{2+}$ ion sensitivity, an established inhibitor of apoptotic expression. Endonuclease activity per se is apoptogenetic and mechanistically convergent with the mitotic catastrophe pathway in the proliferative cycle.
\end{abstract}

Keywords: micrococcal nuclease; apoptosis; mitotic catastrophe; interphase chromosome condensation

Abbreviations: MNase, micrococcal nuclease; TdT, terminal deoxynucleotidyl transferase; NR, neutral red; PBS, phosphate buffered saline; FS, forward scattering; TUNEL, terminal deoxynucleotidyl transferase (TdT)-mediated dUTP-digoxi- genin $3^{\prime} \mathrm{OH}$ end-labelling; PI, propidium iodide; FIGE, field inversion gel electrophoresis; H\&E, haematoxylin eosin; TEM, transmission electron microscopy

\section{Introduction}

Nucleosomal degradation in apoptosis was first described by Wyllie (1980) and subsequently documented in diverse apoptotic systems (Schwartzmann and Cidlowski, 1993). Large fragment cleavage at $50 \mathrm{~kb}$ chromosome loop anchorage sites have also been implicated as the committed step of apoptosis, initiating a 'preapoptotic' state that progresses into apoptosis (Cohen et al, 1994; Walker et al, 1994; Cidlowski et al, 1996). The notion that DNA damage is the leading candidate for initiating apoptotic cell death (Corcoran et al, 1994) seems supported by the demonstration of apoptotic-like features of exogenous (Arends et al, 1990), and endogenous (Montague and Cidlowski, 1996; Khodarven and Ashwell, 1996) nuclease activity applied to isolated nuclei. However it has not been shown as an apoptogen in whole cells.

On the other hand, genomic damage induced by a variety of DNA-damaging agents such as ionizing radiations, alkylating antimetabolites and mutagens, could produce mitotic catastrophe condensations (Denison and May, 1994; Kondo, 1995), a phenomenon that have been causally related to apoptosis via aberrant or premature cell cycle kinase activation (Shi et al, 1994; Bedi et al, 1995; Heald et al, 1993). Comparative molecular and morphological similarities between apoptosis and mitotic catastrophe have also been noted, suggesting common death and division pathways (King and Cidlowski, 1995). 'Chromatin patches' that are said to resemble partly condensed chromosomes and partly apoptotic chromatin condensation have recently been shown following oxidative stress (Dini et al, 1996). Oxidative stress signals precede endonuclease activation in the apoptotic pathway (Fernandez et al, 1995) and apparently mediates both cell proliferation and apoptosis (Sundaresan et al, 1996; Sit and Chen, 1997). The demonstration of endonuclease activity as the mechanistic causation of both apoptotic and interphasic chromosome condensations resembling a mitotic catastrophe would focus the convergence of death and division pathways through this precipitating step.

\section{Results and Discussion}

Internalization prepulse

Whole human Chang liver cells received a $1 \mathrm{~min}$ prepulse of $\mathrm{pH} 5.01 \%$ Bouin's fluid in PBS to promote internalization. The 
brief acidic prepulse did not affect cell viability as demonstrated by growth curve studies over a 6 day period (Figure $1 \mathrm{~A})$. Means of independent samples between prepulsed and non-prepulsed cells were not significantly different at $95 \%$ confidence limits (Student's $t$-test, double tail $/ t /=1.8195 \mathrm{e}-1$, $\mathrm{P}=8.5925 \mathrm{e}-1, P<0.05)$. That internalization was enhanced by the acidic prepulse was demonstrated using neutral red (NR) uptake studies shown in Figures $1 \mathrm{~B}-\mathrm{C}$ and $2 \mathrm{~A}-\mathrm{C}$. Flow cytometric cell-by-cell evaluation of NR uptake showed a marked increase after the acidic prepulse (Figure 1B cf. 1C). NR uptake is an established test of cell viability, not cell death (Goldberg and Frazier, 1989; Zhang et al, 1990). NR enters the cell via endocytic internalization that is dependent on active membrane flow and fusion mechanisms in viable cells. Hence internalized NR is sequestered inside membranebound vacuolar structures that can be subsequently extracted and the amount of internalized dye quantitated as a cell viability index (Sigma Cell Culture Reagents, 1994). Endocytic internalization of NR results in discrete containment of the internalized dye in membrane-bound vacuolar structures of the cytoplasm, hence the punctate cytological appearance (Figure 2A, untreated control). After a $1 \mathrm{~min}$ prepulse of acidic $1 \%$ Bouin's fluid in PBS, NR, internalization was enhanced, causing a further filling-up of the cytoplasmic membrane-bound vacuoles and channels which remained discrete despite the engorgement, without noticeable leak into the cytosol (Figure 2B-C). This is in contradistinction to the entry of trypan blue that is used to mark dead cells or cells with loss of viability, since trypan blue goes into the cytosol through damaged or porated plasma membranes, producing a diffuse blue staining of both the cytoplasm and nucleus. Internalized $\mathrm{NR}$ in discrete membrane-bound structures, is normally excluded from the interphase nucleus but not from prophase or telophase mitotic nuclei, especially tumorigenic ones (Sit et $a l, 1992 b)$. With an acidification prepulse followed by recovery to physiological $\mathrm{pH}$ levels, NR is also sequestered inside the nuclei of interphase cells (Figure $2 \mathrm{C}$ ), stimulating the mitotic state (Sit et al, 1996a,c). We have previously demonstrated that an acidification prepulse followed by reincubation in physiological pH buffers (acidification-and-recovery) is capable of promoting endocytic internalization of a diverse range of macromolecules, from supravital dyes and oligonucleotides, to plasmids, 2 million mol.wt dextrans and latex beads of $2 \mu \mathrm{m}$ diameter. More importantly, the internalized macromolecules entered the nucleus where they accumulated, and in the case of internalized plasmids, carrying the lacZ gene, the human Chang liver cells subsequently expressed this foreign gene with continuing cell cycling, showing its functional integration into the cellular genome (Sit et al, 1990, 1991, 1996a, 1996b; Sit, 1996).

\section{Genomic profile of MNase on whole cells}

(1) Sub-G1 apoptotic peak with cell shrinkage evaluated by flow cytometry Figure 3 shows the genomic content of the human Chang liver cell population after MNase digestion (16 units $/ \mathrm{ml}$ for $1 \mathrm{~h}$ ), evaluated cell-by-cell by flow cytometry. Figure $3 \mathrm{~A}$ shows the cell cycle profile of the control cell population which was given a 1 min acidic (1\% Bouin's) prepulse but without MNase treatment. The MNase-treated

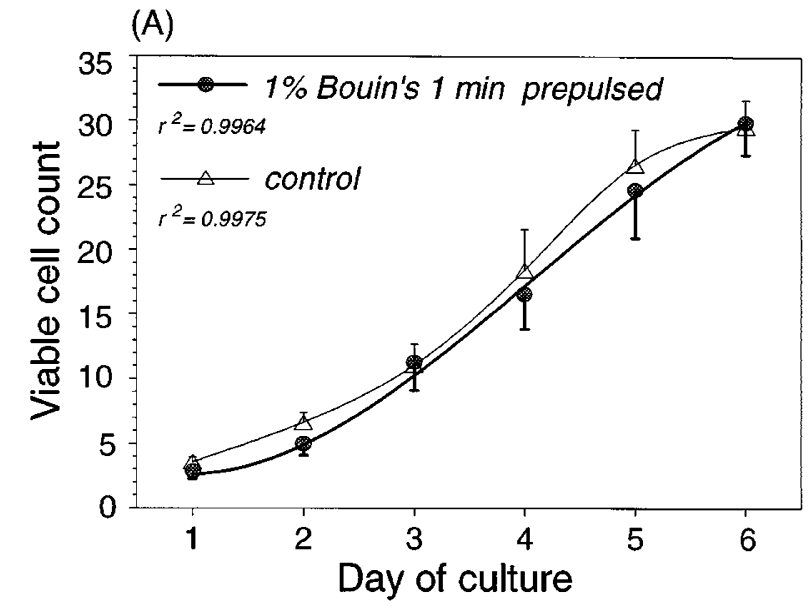

(B)

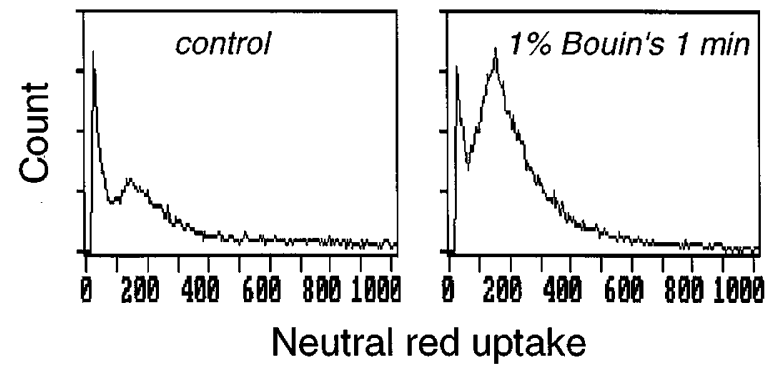

Figure 1 Growth curve and neutral red (NR) uptake of cells given a $1 \mathrm{~min}$ prepulse with $1 \%$ Bouin's in PBS. (A) Growth of prepulsed and non-prepulsed (control) cells were not significantly different over 6 days at $95 \%$ confidence limits (error bars $=2 S . E ., n=3)$. $(B-C)$ NR uptake of prepulsed cells was markedly enhanced

population (Figure 3B) had a distinctive so-called 'apoptotic peak' in the sub-G1 (sub-2N) position (Figure 3Biii) representing genomic degradation with apoptotic cells and bodies (Darzynkiewicz et al, 1997; Tounekti et al, 1995; Rabinovitch, 1994). The sub-G1 apoptotic peak has also been labelled as ' $\mathrm{A}_{0}$ ' (Telford et al, 1994; Fraker et al, 1995). Concurrent with genomic degradation was cell shrinkage (downsizing), a hallmark of the apoptotic response that was originally described as 'shrinkage necrosis' (Wyllie et al, 1980). Downsizing (Figure 3Biii cf. 3Aiii) was demonstrated by laser beam forward scattering (FS), a parameter that is proportional to the cell particle size (Sherwood and Schmike, 1995).

(2) Large $(50 \mathrm{~kb})$ and small (200 bp) fragment genomic degradation typical of apoptosis The time sequence of genomic degradation following MNase digestion was shown to be a 2 stage sequential process involving large and small fragment genomic degradation (Figure 4A-B), similar to the degradation sequence described in a number of apoptotic systems (Oberhammer et al, 1993; Brown et al, 1993; Cohen et al, 1994; Walker et al, 1994; Cidlowski et al, 1996). At $30 \mathrm{~min}$, a $50 \mathrm{~kb}$ band (corresponding to the $48.5 \mathrm{~kb}$ band indicated by an arrowhead in the marker lane, first lane at leftmost side) was clearly resolved (Figure 4A). 

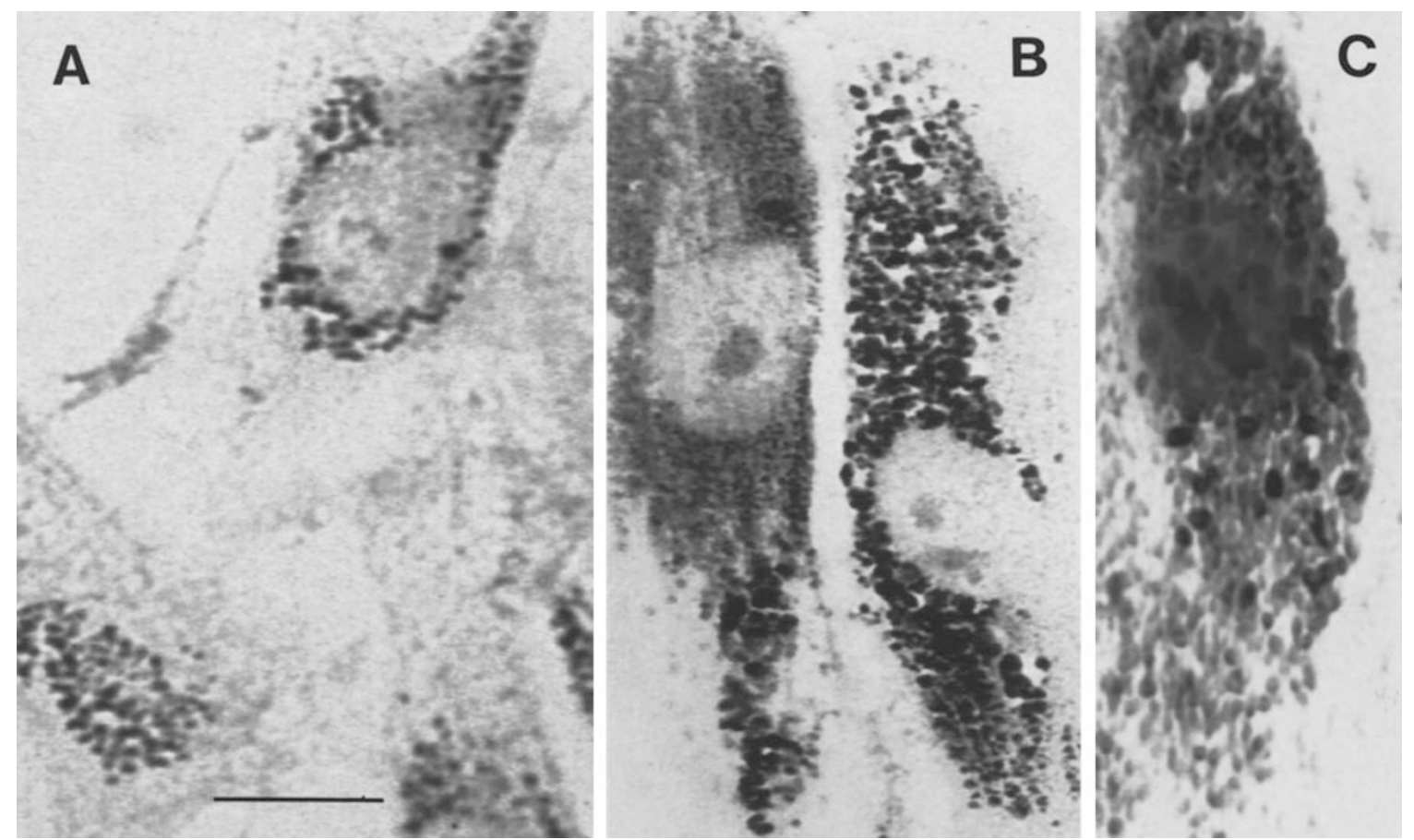

Figure 2 Cytological profiles of NR uptake. (A) Control untreated cells. Discrete punctate sequestration of NR, largely excluded from the nucleus of interphase cells. (B-C) After 1 min prepulse with 1\% Bouin's fluid in PBS, NR uptake was enhanced. (C) NR could be found sequestered inside the nucleus of interphase cells. The nuclear barrier was broken with the acidification prepulse. Bar $=10 \mu \mathrm{m}$

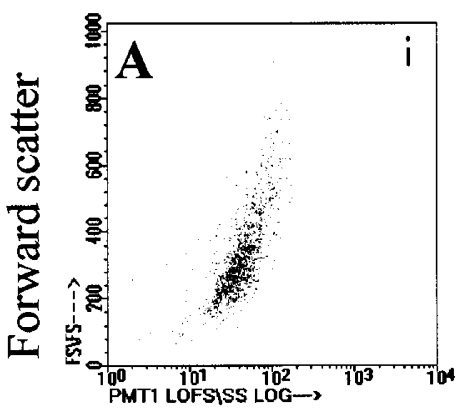

\section{Log side scatter}

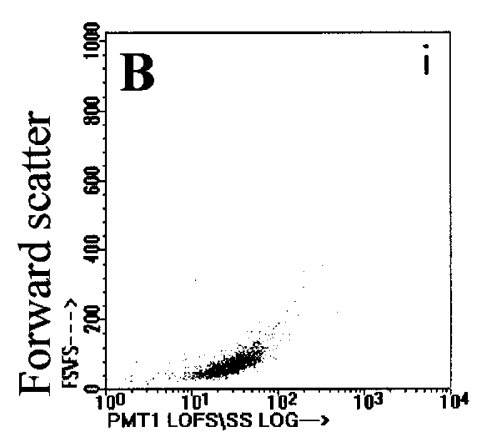

Log side scatter

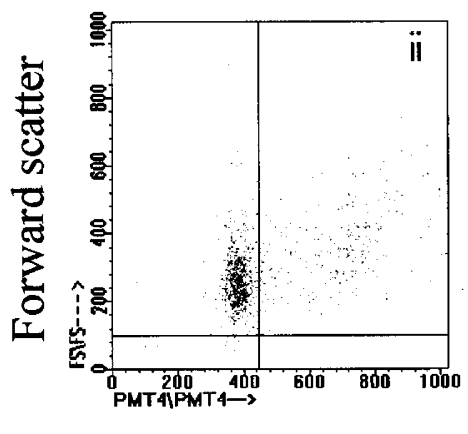

DNA content

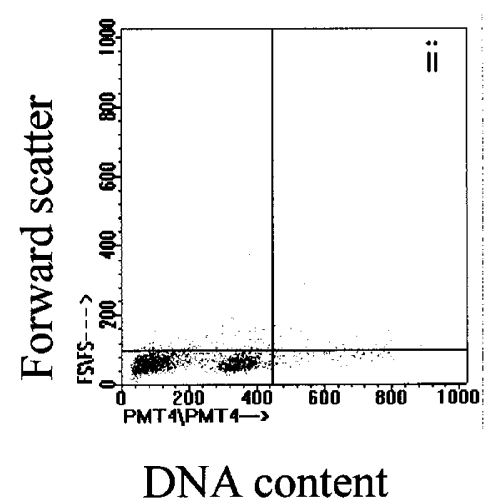

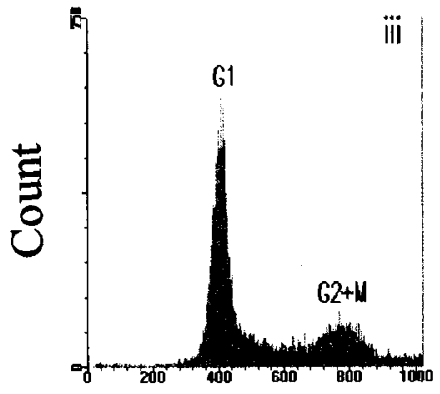

DNA content

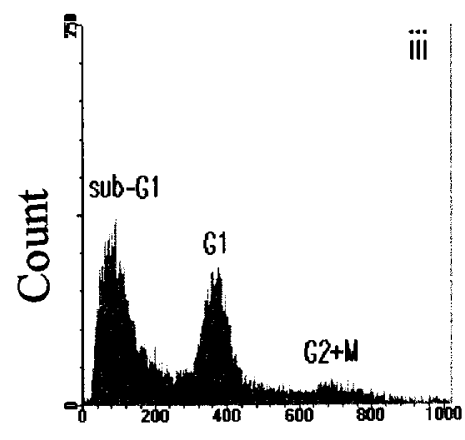

DNA content

Figure 3 Genomic profile after micrococcal nuclease (MNase) incubation at 16 units $/ \mathrm{ml}$ for 60 min. Flow cytometric DNA cell cycle analysis of (A) control undigested whole cells, and (B) MNase-digested whole cells. A sub-G1 'apoptotic peak' developed with the MNase incubation. Both control and MNase-treated populations had $1 \mathrm{~min}$ acidification prepulse with $1 \%$ Bouin's in PBS 

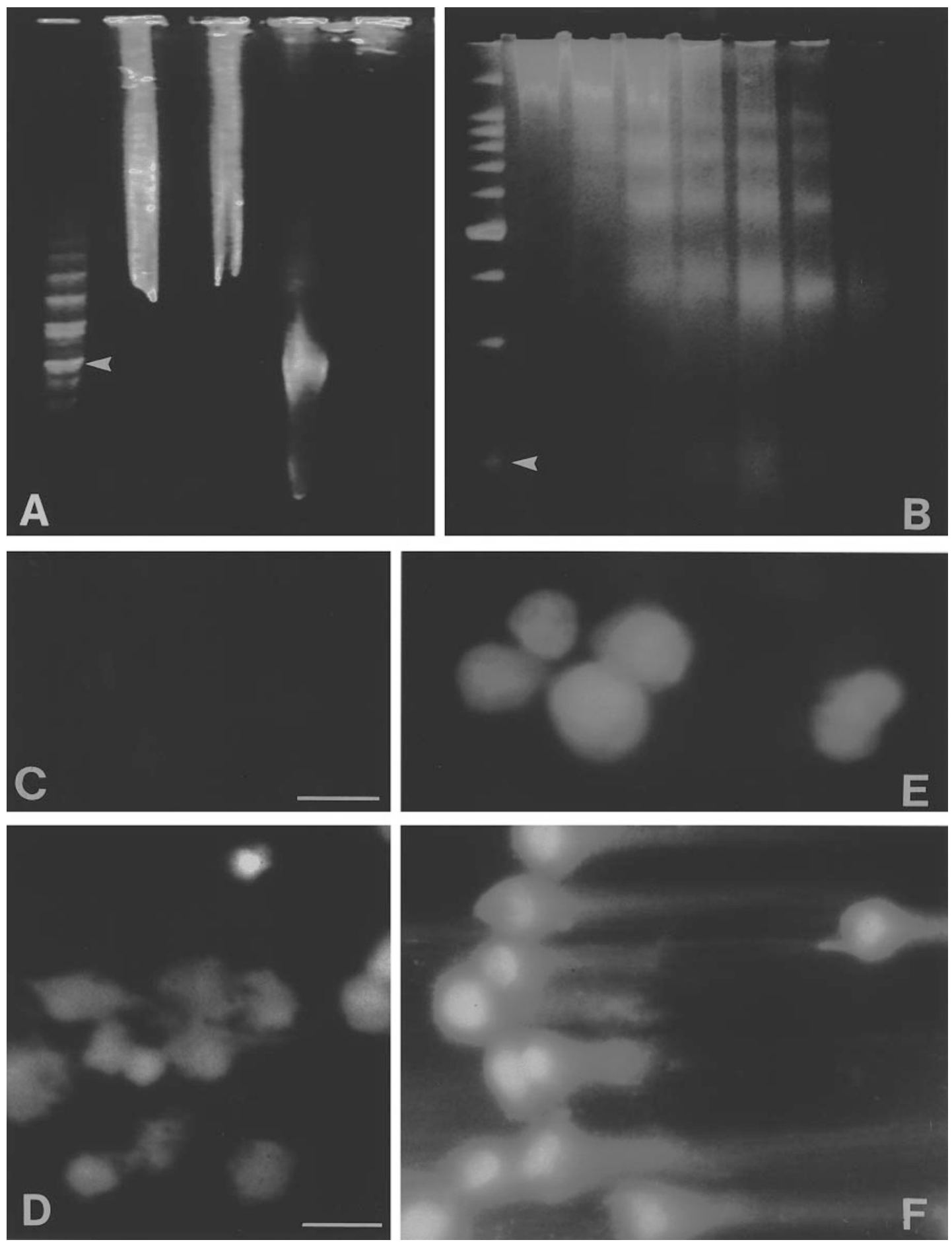

Figure 4 Genomic profile after micrococcal nuclease (MNase) incubation at 16 units/ml. The lanes are numbered sequentially from left to right. (A) FIGE (field inversion gel electrophoresis) evaluating large fragment genomic degradation. Lane 4, digested with MNase for $30 \mathrm{~min}$, showed a $50 \mathrm{~kb}$ band. Lane 1 is the New England Biolab 'Midrange PFG marker' in main steps of $48.5 \mathrm{~kb}$ where the first main $48.5 \mathrm{~kb}$ band is marked by an arrowhead. Lanes 2 and 3 are the 5 and 10 min MNase-digested populations, respectively. Lane 5 is the undigested control population (the right most lane in (A)). (B) Normal agarose gel electrophoresis evaluating small fragment genomic degradation. Lane 1 is the Promega ' $100 \mathrm{bp}$ ladder marker' where the $200 \mathrm{bp}$ band is indicated by an arrowhead. The $500 \mathrm{bp}$ band is the typical brightest landmark band of the Promega $100 \mathrm{bp}$ ladder marker. Lane 2 is the control undigested population. Lanes 3 to 9 had their cell populations incubated with MNase for times ranging from 30 to $90 \mathrm{~min}$, in $10 \mathrm{~min}$ incremental intervals, respectively. The clearest nucleosomal (200 bp) laddering pattern was seen in lane 6 (the $60 \mathrm{~min}$ MNase digested population). (C-D) Terminal deoxynucleotidyl transferase (TdT)-mediated labelling (TUNEL) of $3^{\prime} \mathrm{OH}$ fragmentation in undigested $(\mathbf{C})$, and digested $(\mathbf{D})$ populations. Bar $=10 \mu \mathrm{m} .(\mathbf{E}-\mathbf{F})$ Neutral comet single cell electrophoresis assay for double strand DNA breaks in undigested $(\mathbf{E})$, and digested $(\mathbf{F})$ populations 
The marker was a MidRange PFG Marker I (New England BioLabs) where the bands above the arrowhead are in steps of $48.5 \mathrm{~kb}$. Lanes 2 and 3, were at incubation times of 5 and $10 \mathrm{~min}$ respectively. Lane 4 was the control or undigested cells. The $50 \mathrm{~kb}$ band in apoptotic profiles is suggested as being from chromosome 'loops' released by digestion at their anchorage sites. DNA digestion is known to cause chromatin compaction (Mpoke and Wolff, 1996) with associated cell shrinkage in a 'preapoptotic' state that seems already committed to self-destruction.

Figure 4B shows genomic degradation down to nucleosomal $200 \mathrm{bp}$ level (corresponding to the $200 \mathrm{bp}$ band indicated by the arrowhead in the marker lane, first lane at leftside of Figure 4B). The marker was the Promega $100 \mathrm{bp}$ DNA Ladder where the bands are in steps of $100 \mathrm{bp}$, and the $500 \mathrm{bp}$ band is readily identified as being especially bright). Lane 2 (immediately to the right of the marker lane) was the control with undigested cells. Each subsequent lane thereafter were of digested cells at incubation times of 30 to $90 \mathrm{~min}$ in $10 \mathrm{~min}$ steps. The $200 \mathrm{bp}$ or nucleosomal band was visible at only the later stages of digestion, viz., 60 min incubation time. Oligonucleosomal laddering patterns can be seen from $50 \mathrm{~min}$ incubation onwards, and disappearing at 80 to $90 \mathrm{~min}$ incubation. The laddering pattern of small fragment genomic degradation is generally seen as a biochemical hallmark of apoptosis. It was produced here in whole cells, following resolution of the $50 \mathrm{~kb}$ fragment, as documented in a number of apoptotic responses.

When demonstrated in isolation, either large or small fragment degradation appears less informative since it has individually been associated with both apoptosis and necrosis (Bicknell and Cohen, 1995; Kataoka et al, 1995; Bortner et al, 1995; Cidlowski et al, 1996).

(3) Specific labelling of 3' $\mathrm{OH}$ termini of fragmented DNA by TUNEL Double strand DNA fragmentation with 3 '-OH termini characteristic of apoptosis was shown by specific terminal deoxynucleotidyl transferase (TdT)-mediated dUTP-digoxigenin $3^{\prime} \mathrm{OH}$ end-labelling (TUNEL). Control nuclei (Figure 4C) without fragmentation had no fluorescence. Figure 4D shows the $60 \mathrm{~min}$ MNase-incubation sample which had clear nucleosomal laddering in gel electrophoresis evaluation. Higher fluorescence indicated more DNA fragmentation particularly in the more shrunken cells, showing the association between genomic fragmentation and cell shrinkage in the apoptotic response.

(4) Comet single cell electrophoresis assay in nondenaturing ('neutral') conditions Controls without MNase digestion had no comet tails (Figure 4E). After $60 \mathrm{~min}$ MNase digestion (Figure 4F) the cells showed bright fluorescence after PI-DNA binding, and all cells showed positive comet tails. The comet assay has been shown to be capable of distinguishing apoptotic from necrotic genomes when performed in nondenaturing ('neutral') conditions as opposed to denaturing or 'alkaline lysis' conditions which detect single strand breaks rather than double strand breaks (Olive et al, 1991; Fairbairn and O’Neill, 1996).
The genomic profiles were consistent with an apoptotic response from the whole cell MNase incubation.

\section{Cytological profiles of MNase-treated whole cells}

(1) Propidium iodide ( $P I)-D N A$ binding profiles Figure $5 \mathrm{~A}$ is the control state from PI-DNA binding without MNase treatment. No chromatin condensation could be seen in the nuclei. At 60 min incubation with MNase (16 units/ml) (Figure $5 B$ ) the chromatin was highly condensed, manifesting clumpy morphologies of diverse sizes. Thick curved arrow points to a nucleus with the hemilunar marginated chromatin condensation characteristic of an apoptotic cell. The other cells had punctate condensation forms with distinctive dispositions, such as (a) condensing around nucleolar areas which are the non-fluorescent areas (thick straight arrow) from RNase treatment in PI-DNA binding preparations, (b) threadlike
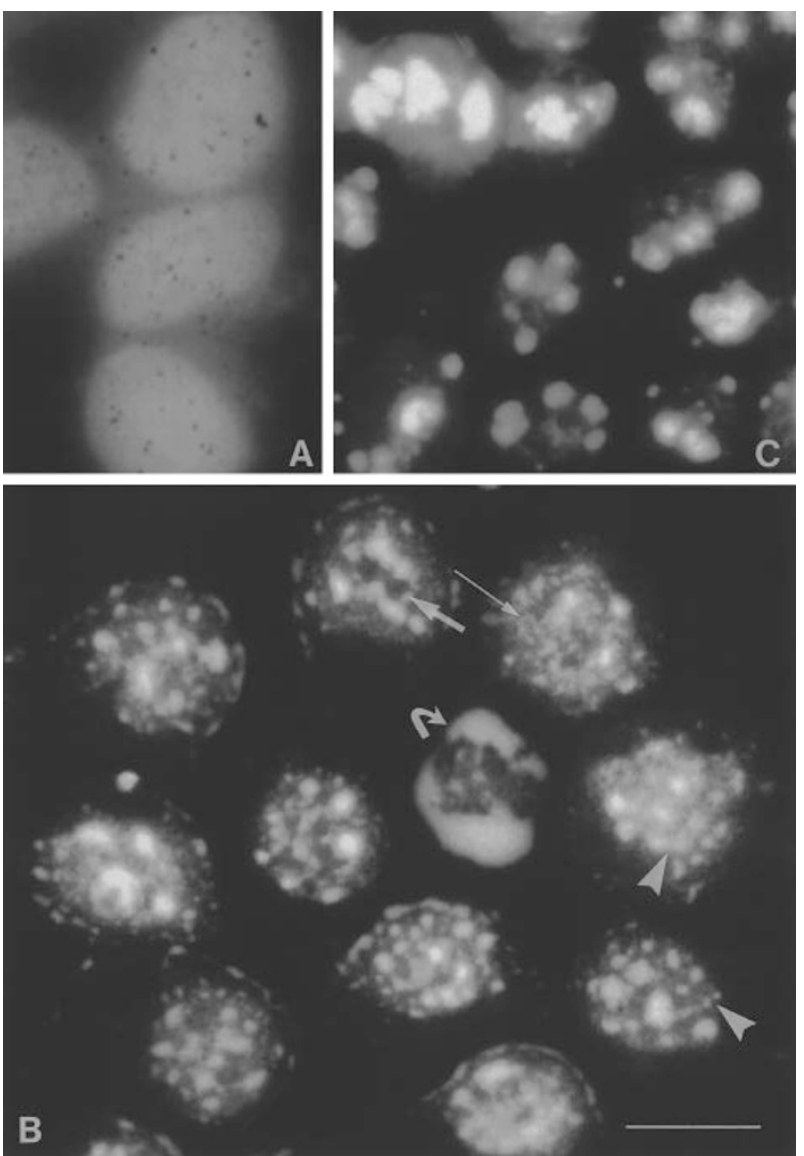

Figure 5 Cytological profile after micrococcal nuclease (MNase) incubation at 16 units $/ \mathrm{ml}$ : propidium iodide (PI)-DNA binding viewed by incident fluorescence microscopy. (A) control undigested population. (B) $60 \mathrm{~min}$ MNase-digested population showing interphasic chromosome condensation, viz., (i) threadlike configurations indicated by thin arrow, (ii) nucleolar areas surrounded by condensed chromosomes indicated by thick arrow, (iii) homologous pairing in parallel orientation indicated by arrowhead. Hemilunar condensation, a classical apoptotic hallmark is indicated by the curved arrow. Nuclear buddings are evident in many cells. (C) 70 min MNase-digested population, showing nuclear fragmentation breaking up into micronuclei and apoptotic bodies, the typical hallmarks of terminal apoptosis. Bar $=10 \mu \mathrm{m}$ 
chromosome configurations (thin arrow), (c) condensations in parallel alignments characteristic of homologous pairing of chromosomes in interphase cells (arrowhead). Buddings at the nuclear periphery can be seen in a number of cells. Figure $5 \mathrm{C}$ was the $70 \mathrm{~min}$ MNase-incubation profile marked by nuclear fragmentation into micronuclei and apoptotic bodies, the hallmarks of terminal apoptosis.

(2) Haematoxylin-eosin (H\&E) profiles Large chromatin clumping typical of apoptosis is shown in a telophase doublet (Figure 6A). Figure 6B shows a pair of interphase nuclei with highly condensed chromatin aggregations and nuclear buddings that also typify the apoptotic response. Figure 6C-E show interphasic chromosome condensation forms. Figure 6C shows condensed chromosomes in parallel alignment typical of homologous chromosome pairing in interphase cells (LaSalle and Lalande, 1996), and a common feature in premature chromosome condensations of interphase cells induced by mitotic-interphase cell fusions (Rao, 1977; Ibid, 1990). Interphasic chromosome condensations are also characterized by their tendency to surround nucleolar areas producing ringformations, and shown in Figure 6C) (arrowed). The G1 chromosome condensations from entwined thin threadlike configurations (Figure 6D). The two features of interphasic chromosomal condensation, viz., homologous pairing (arrowhead) and nucleolar area surrounded by chromosomes (arrow) were also evident here. In a well-resolved G2 state, such as shown in Figure 6E, these two characteristics of interphasic chromsomes, viz. homologous pairing of chromosomes (arrowhead), and nucleolar areas marked by chromosomes forming rings around them (arrows), were also seen. These G2 chromosomes were distinguished by centromeric constrictions, sister chromatids, and chromomeric light and dark staining band-like areas (a distinctive chromosome characteristic) along their arms.

(3) Ultrastructure profile in transmission electron microscopy Figure 7A shows the control state without MNase digestion. Nuclear chromatin is largely diffuse without distinctive chromatin condensations. Figure 7B-D show fluffy threadlike chromosome condensations, homologous pairing and condensations around the nucleolus. These are features characteristic of interphasic chromosome condensation. In Figure 7B the smaller arrows point to homologous pairing of condensed chromosomes in ' $\mathrm{V}$ ' formations, and the larger arrow points to the nucleolus ringed by condensed chromosomes. Fluffy bands of chromosome condensations are also shown in Figure 7C which is a peripheral section of the nucleus. Hemilunar condensation typical of apoptosis is shown in Figure 7D. Curved arrow points to the large gathering of prominent microvillous anchors from a much retracted apoptotic cell. Prominent microvillous anchors and endocytic vacuoles are features of cell retraction, seen in induced cell retraction of interphase cells, spontaneous retraction of mitotic cells and serum-deprivation induced apoptosis, that could contribute to rounding and substrate detachment (Sit et al, 1990, 1992a, 1993, 1994; Sit, 1996).
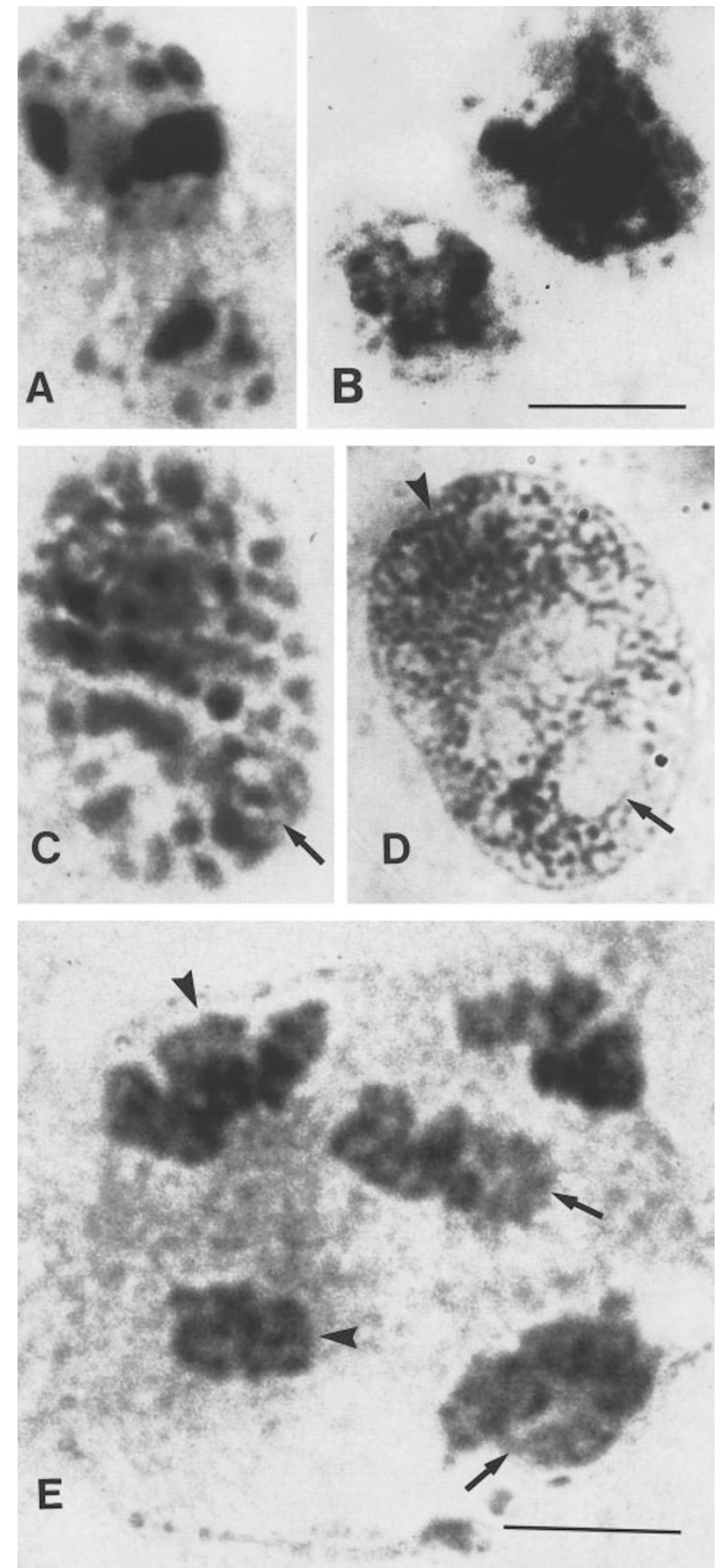

Figure 6 Cytological profile after micrococcal nuclease (MNase) incubation at 16 units/ml for $60 \mathrm{~min}$ : haematoxylin-eosin (H\&E) staining viewed by transmitted light microscopy. (A-B) Apoptotic profiles marked by large clumpy condensations and nuclear buddings. (C-E) Interphasic chromosome condensations (see text for details). Arrows point to nucleolar areas surrounded by condensed chromosomes. Nucleoli presence are characteristic of the interphasic state. Arrowheads (D-E) point to homologous pairing which is also an interphasic characteristic. Chromosomes in (D) were thin threadlike bodies indicating a G1 state, before replication. Chromosomes in (E) had sister chromatids, indicating a G2 state, which is after replication. Bar $=10 \mu \mathrm{m}$ applies for $(\mathbf{A}-\mathbf{D})$, and $1 \mu \mathrm{m}$ for $(\mathbf{E})$ 

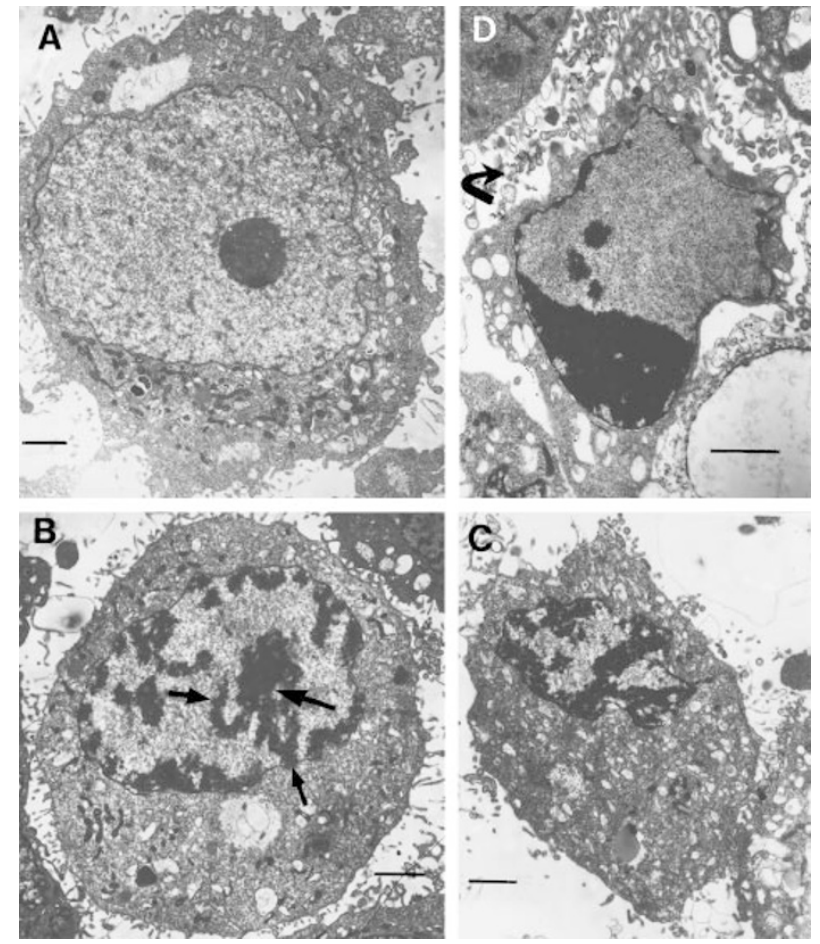

Figure 7 Cytological profile after micrococcal nuclease (MNase) incubation at 16 units $/ \mathrm{ml}$ for $60 \mathrm{~min}$ : Ultrastructural profiles in transmission electron microscopy. (A) Control undigested cell without distinctive chromatin condensation. (B-D) MNase-digested cells with distinctive chromatin condensation. (B-C) show 'fluffy' chromosomal states. Smaller arrows in (B) point to chromosomes with homologous pairing characteristics. The larger arrow points to nucleolus surrounded by 'fluffy' chromosomes. (D) shows classical homogeneous 'hemilunar' margination in apoptosis. Curved arrow points to the large gathering of retraction microvillus anchors of the cell. Bars $=1 \mu \mathrm{m}$

(4) Nuclear shrinkage evaluated by confocal laser microscopy image analysis One of the well established hallmarks of apoptosis is nuclear shrinkage demonstrated in isolated nuclei after MNase treatment by Arends et al (1990), and shown here in whole cells using confocal image analysis of nuclei highlighted by PI-DNA binding (Figure 8 , sample size $n=50$ ). The mean nuclear size of the control population was $127.60 \mu \mathrm{m}^{2}( \pm$ S.D. 33.85) while that of the MNase treated population $(16 \mathrm{u} / \mathrm{ml} 1 \mathrm{~h})$ was $74.12 \mu \mathrm{m}^{2}$ ( \pm S.D. 41.34). Student $t$-test for independent samples of control and MNase treated populations showed significant difference in their nuclear areas $(|t|=9.1627$, $\mathrm{P}=7.9956 \mathrm{e}-15, P=<0.05)$. The addition of $1 \mathrm{mM} \mathrm{ZnCl} 2$ into the incubation inhibited the change. The mean nuclear area with $\mathrm{Zn}^{2+}$ inhibition was $130.11 \mu \mathrm{m}^{2}$ ( \pm S.D. 40.87). Student $t$-test for independent samples of control and $\mathrm{Zn}^{2+}$. inhibited MNase populations showed no significant difference in their nuclear areas $(|t|=9.2933 \mathrm{e}-1, P=3.5499 \mathrm{e}-1$, $P=<0.05)$. On the other hand, the Student $t$-test for independent samples of MNase-treated and $\mathrm{Zn}^{2+}$-inhibited MNase populations showed significant difference in their nuclear areas $(|t|=7.4629, \mathrm{P}=3.4825 \mathrm{e}-11, P=<0.05) . \mathrm{Zn}^{2+}$ is an established inhibitor of endonuclease activity and

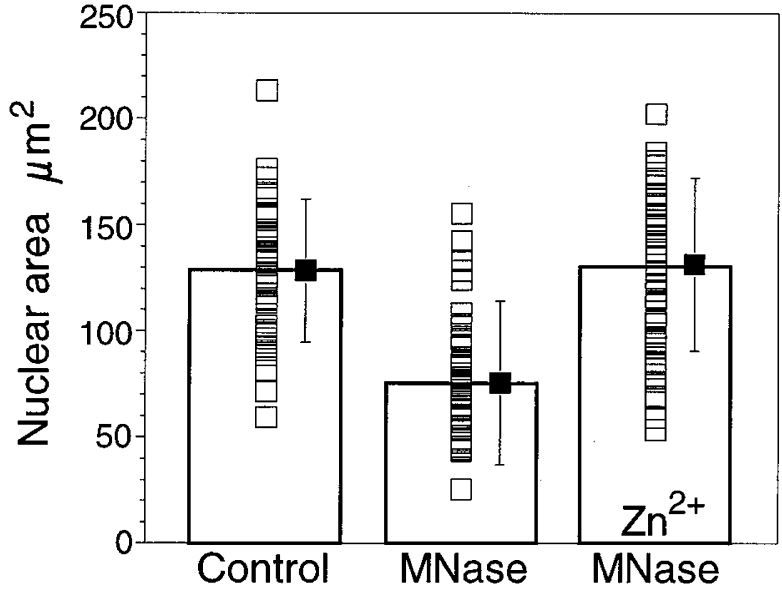

Figure 8 Nuclear sizing of MNase-incubated (16 units/ml for $60 \mathrm{~min}$ ) whole cells by confocal microscopy image analysis. Control and MNase-digested nuclear sizes were significantly different. Control and MNase-digested with $1 \mathrm{mM} \mathrm{ZnCl} 2$ were not different. Evaluated by Student's $t$-test at $95 \%$ confidence limits. $n=50$, bar $=1$ S.D.

apoptotic manifestations (Cidlowski et al, 1996) so that $\mathrm{Zn}^{2+}$-sensitivity is generally perceived as being typical of the apoptotic response.

\section{Conclusions}

The cytological profiles were consistent with an apoptotic response. The MNase activity, in addition, produced various characteristics of interphasic chromosome condensation, resembling a mitotic catastrophe (Heald et al, 1993) and premature chromosome condensation (Rao, 1977, 1990). The combination of genomic and cytological profiling suggested strongly that (a) endonuclease activity is itself apoptogenic, and (b) interphasic chromosome condensation (mitotic catastrophe condensations) and apoptotic condensations are mechanistically convergent processes.

\section{Materials and Methods}

\section{Cell culture}

Monolayer cultures of human Chang liver cells (American Type Culture Collection, ATCC CCL 13) were grown in $25 \mathrm{~cm}^{2}$ culture flasks (Costar, Cambridge, MA, USA), in Dulbecco's modified Eagle's medium (DMEM, Sigma Chemical Co., St Louis, MO, USA) supplemented with $10 \%$ fetal bovine serum (Biological Industries, Kibbutz, Israel) and $10 \% \mathrm{CO}_{2}$ in air, in a $37^{\circ} \mathrm{C}$ incubator. The parallel cultures were seeded using an automatic dispenser (Filamatic vial filter, National Instruments, Baltimore, MD, USA) from a stirred stock suspension.

\section{Growth curve study with and without acidification prepulsing}

Parallel cultures of human Chang liver cells were scraped with a cell scraper (Costar Corp., Cambridge, MA, USA) and triturated using a 
$5 \mathrm{ml}$ syringe with a 21 gauge needle to obtain single cell suspension. The cells were prepulsed for $1 \mathrm{~min}$ in $\mathrm{pH} 5.01 \%$ Bouin's fluid (15 parts of $1.2 \%$ aqueous picric acid, 5 parts of formalin and 1 part of glacial acetic acid) in Dulbecco's phosphate buffered saline (PBS), and then washed twice with PBS, $10 \mathrm{ml}$ each. After the prepulse, the cell suspension was replated in $10 \mathrm{ml}$ DMEM with $10 \%$ serum for 6 days of growth curve studies, sampled each day in triplicate. The viable cell count was made on cells with trypan blue dye exclusion.

\section{Neutral red uptake study}

After the $1 \mathrm{~min}$ acidification (1\% Bouin's) prepulse (see above), $50 \mu \mathrm{l}$ of neural red (NR, Cl 50040, Michrome no. 226, mol. wt. 288.78, Gurr Certistain 34056, BDH Chemicals, Poole, UK) at stock concentration of $10 \mathrm{mg} / \mathrm{ml}$ was added to $2 \mathrm{ml}$ of cell suspension and rocked for $2 \mathrm{~min}$ at room temperature. $5 \mathrm{ml}$ of PBS was added to the cell suspension and spun down. After decanting the staining medium, the cells were resuspended in a small volume of PBS for flow cytometry. Neutral red uptake was measured at the excitation/emission wavelengths of 488/ $635 \mathrm{~mm}$ in FL3 of Coulter EPICS ELITE ESP flow cytometry (Coulter Corporation, Hialeah, FL, USA). Aliquots of the cells were Cytospinned down for examination under light microscopy.

\section{Micrococcal nuclease treatment of whole cells}

After the acidification prepulse, the cells were incubated with micrococcal nuclesae (Worthington Diagnostics, Flow-General, CA, USA, stock solution 16000 units/ml of PBS without $\mathrm{Ca}^{2+}$ or $^{\mathrm{Mg}^{2+}}$ ) at 16 units $/ \mathrm{ml}$ of cell suspension in complete Dulbecco's phosphate buffered saline (PBS with $\mathrm{CaCl}_{2}, \mathrm{MgCl}_{2}, 0.1 \mathrm{~g} / \mathrm{l}$ ) for varying times from $5 \mathrm{~min}$ to $90 \mathrm{~min}$. The micrococcal nuclease-treated cells were subsequently subjected to genomic and cytological profiling as described below.

\section{Flow cytometric cell cycle DNA evaluation}

All control and experimental cells received identical prepulse treatments for $1 \mathrm{~min}$ in $\mathrm{pH}$ 5.0. 1\% Bouin's fluid in PBS, as detailed above for growth curve studies, although no prior treatment is demanded by the method of propidium iodide-DNA binding for flow cytometric cell cycle evaluation of the genomic contents of normal control and apoptotic cells (Zamai et al, 1996). Cells were washed in PBS and then incubated in $1 \mathrm{ml}$ of freshly prepared propidium iodide (PI) (Sigma, St Louis, MO, USA) solution (Tris $1.21 \mathrm{~g} / \mathrm{l}, \mathrm{NaCl} 0.580 \mathrm{~g} / \mathrm{l}$, PI $0.0501 \mathrm{~g} / \mathrm{l}$ ) which contained $30 \mathrm{mg}$ ribonuclease A (RNase A, Type IIA, Sigma) per $5 \mathrm{ml} \mathrm{PI} \mathrm{solution,} \mathrm{added} \mathrm{just} \mathrm{before} \mathrm{incubation.}$ Incubation time was 45 min over an ice bath. Cells were pelleted by centrifugation and washed once in PBS.

$\mathrm{PI}$-stained cells were analyzed for cell cycle phase DNA content in a Coulter EPICS ELITE ESP flow cytometer (Coulter Corporation, Hialeah, FL, USA) with Elite Workstation programme version 4.01, and Multicycle programme version 2.53 (Phoenix Flow Systems, Sorrento Valley, San Diego, USA). The light source was $15 \mathrm{~mW}$ argon laser exciting at $488 \mathrm{~nm}$. The PI-DNA fluorescence intensity was detected at an emission wavelength of $610 \mathrm{~nm}$ and quantitiated as relative channel numbers in FL4. The sample flow and data rate were set respectively at $35 \mu \mathrm{l} / \mathrm{min}$ and $50-80$ events/sec.

\section{Gel electrophoresis}

FIGE (field inversion gel electrophoresis) assay of large fragment genomic degradation Cells were prepared for loading as follows.
$10^{6}$ cells were pelleted in $1.5 \mathrm{ml}$ Eppendorf tubes (autoclaved), and resuspended in $50 \mu \mathrm{l}$ of cell suspension buffer (10 mM Tris, pH 7.2, $20 \mathrm{mM} \mathrm{NaCl}, 50 \mathrm{mM}$ EDTA) maintained at $50^{\circ} \mathrm{C}$. This was mixed with an equal volume of $2 \%$ CleanCut agarose (BioRad) equilibrated to $50^{\circ} \mathrm{C}$ and transferred to plug moulds (BioRad). The genomic plugs were allowed to solidify by cooling to $4^{\circ} \mathrm{C}$ for 10-15 $\mathrm{min}$, before incubation overnight in proteinase $\mathrm{K}$ reaction buffer (100 mM EDTA, pH 7.6, $0.2 \%$ sodium deoxycholate, $1 \%$ sodium lauryl sarcosine, $1 \mathrm{mg} / \mathrm{ml}$ proteinase $\mathrm{K}$ ). Genomic plugs were subsequently washed four times in wash buffer $(20 \mathrm{mM}$ Tris, $\mathrm{pH} 7.6,50 \mathrm{mM}$ EDTA), $1 \mathrm{~h}$ each at room temperature with gentle agitation before pushing into the gel wells of the $15 \times 15 \mathrm{~cm} 1 \%$ Pulse Field Certified Agarose (BioRad) gel. The marker was a 15$300 \mathrm{~kb}$ MidRange PFG Marker I (355-1, New England BioLabs, Beverly, MA). Electrophoresis was in TAE buffer $(40 \mathrm{mM}$ Tris, $40 \mathrm{mM}$ glacial acetic acid, $2.0 \mathrm{mM}$ EDTA, pH 8.0) with $180^{\circ}$ pulse field inversion that was programmed to $6 \mathrm{~V} / \mathrm{cm}$ forward voltage, $4 \mathrm{~V} / \mathrm{cm}$ reverse voltage, with switch times ramped from 1-25 s, using the FIGE Mapper system (BioRad) and ran for $24 \mathrm{~h}$ at $17^{\circ} \mathrm{C}$. After electrophoresis, the gel was stained in freshly prepared Sybr Green I at $30 \mu \mathrm{l}$ stock dye (proprietary mix S-7567 in DMSO, Molecular Probes, Eugene, Oregon) to $100 \mathrm{ml} \mathrm{TAE}$ buffer.

Normal agarose electrophoresis assay of small fragment genomic degradation Cells were prepared for loading as follows. $10^{6}$ cells were pelleted in $1.5 \mathrm{ml}$ Eppendorf tubes (autoclaved), and resuspended in $20 \mu \mathrm{l}$ lysis buffer $(20 \mathrm{mM}$ EDTA, $100 \mathrm{mM}$ Tris, $\mathrm{pH} 8.0,0.8 \%$ sodium lauryl sarcosine). $10 \mu \mathrm{l}$ of $1 \mathrm{mg} / \mathrm{ml}$ RNase type IIA (Sigma, St Louis, MO) was added to the cell suspension and incubated for $1 \mathrm{~h}$ at $37^{\circ} \mathrm{C} .10 \mu \mathrm{l}$ of proteinase $\mathrm{K}(1 \mathrm{mg} / \mathrm{ml}$ proteinase $\mathrm{K}$ (Promega), in $100 \mathrm{mM}$ EDTA of $\mathrm{pH} 8.0,0.2 \%$ sodium deoxycholate, $1 \%$ sodium lauryl sarcosine) was then added and incubated overnight at $50^{\circ} \mathrm{C}$, before loading into the gel. The gel was $15 \times 15 \mathrm{~cm} 2 \%$ Metaphor agarose (50182, FMS Bioproducts, Rockland, ME) in $0.5 \times \mathrm{TBE}$ buffer ( $45 \mathrm{mM}$ Tris, $45 \mathrm{mM}$ boric acid, $1 \mathrm{mM}$ EDTA, pH 8.0) in a horizontal electrophoresis system (Sub-Cell system GT with PowerPac $1000 / 500$ power supply, BioRad Laboratories, Hercules, CA) that ran at $60 \mathrm{~V}$ constant voltage for $9 \mathrm{~h}$ in $0.5 \%$ TBE buffer circulated at $17^{\circ} \mathrm{C}$. The marker was a Promega $100 \mathrm{bp}$ DNA ladder (G210A, Promega, Madison, $\mathrm{WI}$ ). Electrophoresis was performed for $9 \mathrm{~h}$ for the $15 \times 15 \mathrm{~cm}$ gel, at $17^{\circ} \mathrm{C}$ buffer temperature. After electrophoresis, the gel was stained in freshly prepared Sybr Green I (Molecular Probes) in TBE buffer.

\section{Terminal deoxynucleotidyl transferase (TdT)- mediated dUPT nick end-labelling (TUNEL)}

Terminal deoxynucleotidyl transferase (TdT)-mediated dUTP nick endlabelling (TUNEL) highlights $3^{\prime} \mathrm{OH}$ termini of DNA fragmentation which are characteristic of apoptotic DNA fragmentation. The manufacturer's protocol (ApopTag, Oncor, Gaithersburg, USA) was followed. The principle involved was template-independent addition of dUTPdigoxigenin to $3^{\prime} \mathrm{OH}$ ends of the fragmented DNA catalyzed by exogenous terminal deoxynucleotidyl transferase (TdT), which was followed by binding with fluorescein-labelled antidigoxigenin antibody for detection. Procedure was previously described (Swe et al, 1996).

\section{Comet assay/single cell gel electrophoresis (neutral assay}

The neutral comet assay used was essentially that described by Olive et al. (1991). Sand-blasted (frosted) microscope slides were 
coated wth a thin layer of $0.75 \%$ NMPA (normal melting-point agarose, Promega, V312A, Promega Corporation, Madison, WI, USA). The NMPA coating were solidified at room temperature $\left(24^{\circ} \mathrm{C}\right)$ for $5 \mathrm{~min}$. $20 \mu \mathrm{l}$ of cell suspension mixed with $80 \mu \mathrm{l}$ of $0.75 \%$ LMPA (low melting-point agarose, V283A, Promega) were added onto the NMPA-coated slide. The slides were kept at $4^{\circ} \mathrm{C}$ for $5 \mathrm{~min}$ for gelling. Subsequently, all slides were immersed in the neutral lysing solution (154 mM Sucrose, $10 \mathrm{mM}$ Tris, $10 \mathrm{mM}$ EDTA, $0.5 \%$ Triton $\mathrm{X}-100$, with freshly added $10 \% \mathrm{DMSO}, \mathrm{pH} 8.3$ ) at $4^{\circ} \mathrm{C}$ for $1 \mathrm{~h}$. Slides were then placed in a horizontal gel electrophoresis apparatus (GIBCO BRL Horizontal 20-25 Life Technologies, Gaithersburg, MD, USA) with freshly prepared TBE buffer (90 mM Tris, $2 \mathrm{mM}$ EDTA, $90 \mathrm{mM}$ Boric acid) and equilibrated for $20 \mathrm{~min}$ before starting electrophoresis. Electrophoresis was conducted at constant power setting of $300 \mathrm{~mA}$ for 344 volt-hours. After electrophoresis, the slides were neutralized in $0.4 \mathrm{M}$ Tris buffer for $5 \mathrm{~min}$, before staining with $200 \mu \mathrm{l}$ of propidium iodide (PI) at $5 \mathrm{ng} / \mathrm{ml} \mathrm{H}_{2} \mathrm{O}$. The slides were immediately examined under an incident light fluorescence microscope (Reichert-Jung).

\section{Propidium iodide (PI) staining for incident fluorescence microscopy}

Cells were incubated in $1 \mathrm{ml}$ of freshly prepared propidium iodide $(\mathrm{PI})$ (Sigma, St Louis, MO, USA) solution (Tris $1.21 \mathrm{~g} / \mathrm{l}, \mathrm{NaCl} 0.589 \mathrm{~g} / \mathrm{l}, \mathrm{PI}$ $0.0501 \mathrm{~g} / \mathrm{l}$ ) which contained $30 \mathrm{mg}$ ribonuclease A (RNase A, Type IIA, Sigma) per $5 \mathrm{ml} \mathrm{PI}$ solution, added just before incubation. Incubation time was 45 min over an ice bath. Cells were pelleted by centrifugation and washed with PBS and then Cytospinned down on slides (Cytospin-2 Shandon). The slides were observed under the Reichert-Jung Univer fluorescence microscope (Leica, Cambridge, UK) at excitation/emission wavelength of $510 / 630 \mathrm{~nm}$.

\section{Haematoxylin and eosin (H\&E) staining for light microscopy}

Cell suspension was plated on slides by Cytospinning (Cytospin-2, Shandon Southern Products, Astmoor, Cheshire, UK) and stained $10 \mathrm{~min}$ in haematoxylin before differentiation in acid alcohol until red. Slides were washed thoroughly in tap water until blue and counterstained $1 \mathrm{~min}$ in $0.5 \%$ eosin, rinsed in water, dehydrated with two changes each of $95 \%$ and $100 \%$ alcohol.

\section{Transmission electron microscopy}

For transmission electron microscopy (TEM), cells were processed as previously described (Sit et al, 1992a). Examination was done in a JEOL 1200EX.

\section{Confocal laser microscope image analysis of nuclear area and fluorescence}

PI stained cells were washed with PBS and an aliquot was spun down onto clean slides in the Cytospin-2. Image analysis were performed with the Carl Zeiss LSM 410 Inverted Laser Scan Confocal Microscope (Carl Zeiss Inc., Thornwood, NY, USA) equipped with Windows-based LSM 4 software version 3.5., and a $488 \mathrm{~nm}$ argon laser using a laser power of $10 \%$.

\section{Acknowledgements}

We thank the National University of Singapore for funding this research. LY is supported by a University Research Scholarship.

\section{References}

Arends MJ, Morris RG and Wyllie AH (1990) Apoptosis: the role of the endonuclease. Am. J. Path. 136: 595-607

Bedi A, Barber JP, Bedi GC, el-Deiry WS, Sidransky D, Vala MS, Akhar AJ, Hilton J and Jones RJ (1995) BCR-ABL-mediated inhibition of apoptosis with delay of G2/M transition after DNA damage: a mechanism of resistance to multiple anticancer agents. Blood 86: 1148-1158

Bicknell GR and Cohen GM (1995) Cleavage of DNA to large kilobase pair fragments occurs in some forms of necrosis as well as apoptosis. Biochem. Biophys. Res. Commun. 207: 40-47

Bortner CD, Oldenberg NBE and Cidlowski JA (1995) The role of DNA fragmentation in apoptosis. Trends Cell Biol. 5: 21-26

Brown DG, Sun X-M and Cohen GM (1993) Dexamethasone-induced apoptosis involves cleavage of DNA to large fragments prior to internucleosomal fragmentation. J. Biol. Chem. 268: 3037-3039

Cidlowski JA, King KL, Evens-Storm RB, Montague JW, Bortner CD and Huges FM Jr (1996) The biochemistry and molecular biology of glucocorticoid-induced apoptosis in the immune system. Recent Prog. Horm. Res. 51: 457-490

Cohen GM, Sun XM, Fearnhead H, MacFarlane M, Brown DG, Snowden RT and Dinsdale D (1994) Formation of large molecular weight fragments of DNA is a key committed step of apoptosis in thymocytes. J. Immunol. 153: 507-516

Corcoran GB, Fix L, Jones DP, Moslen MT, Nicotera P, Oberhammer FA and Buttyan (1994) Apoptosis: Molecular control point in toxicity. Toxicol. Appl. Pharmacol. 128: $169-181$

Darzynkiewicz Z, Juan G, Li X, Groczyca W, Murakami T and Tragonos F (1997) Cytometry in cell necrobiology: Analysis of apoptosis and accidental cell death (necrosis). Cytometry 27: 1-30

Denison SH and May GS (1994) Mitotic catastrophe is the mechanism of lethality for mutations that confer mutagen sensitivity in Apspergillus nidulans. Mutat. Res 16: $193-202$

Dini L, Coppola S, Ruzitu MT and Ghibelli L (1996) Multiple pathways for apoptotic nuclear fragmentation. Exp. Cell Res. 233: 340-347

Fairbairn DW and O'Neill KL (1996) The neutral comet assay is sufficient to identify an apoptotic window by visual inspection. Apoptosis 1: 91-94

Fernandez A, Kiefer J, Fosdick L and McConkey DJ (1995) Oxygen radical production and thiol depletion are required for $\mathrm{Ca}^{2+}$-mediated endogenous endonuclease activation in apoptotic thymocytes. J. Immunol. 155: 5133-5139

Fraker PJ, King LE, Lill-Elghanian D and Telford WG (1995) Quantitation of apoptotic events in pur and heterogenous populations of cells using the flow cytometer. In Methods in Cell Biology vol 46 (eds Schwartz LM and Osborne BA). Academic Press, San Diego, pp 57-76

Goldberg AM and Frazier JM (1989) Alternative to animals in toxicity testing. Sci. Am. 261: $16-22$

Heald R, McLoughlin M and McKeon F (1993) Human Wee1 maintains mitotic timing by protecting the nucleus from cytoplasmically activated cdc2 kinase. Cell 74: $463-474$

Kataoka A, Kubota M, Wakazono Y, Okuda A, Bessho R, Lin YW, Usami I, Akiyama Y and Furusho K (1995) Association of high molecular weight DNA fragmentation with apoptotic or non-apoptotic cell death induced by calcium ionophore. FEBS Lett. 364: 264-267

Khodarev NN and Ashwell JA (1996) An inducible lymphocyte nuclear $\mathrm{Ca}^{2+} / \mathrm{Mg}^{2+}$. dependent endonuclease associated with apoptosis. J. Immunol. 156: 922-931

King KL and Cidlowski JA (1995) Cell cycle and apoptosis: common pathways to life and death. J. Cell. Biochem. 58: 175-180

Kondo S (1995) Apoptosis by antitumor agents and other factors in relation to cell cycle checkpoints. J. Radiat. Res. Tokyo 36: 56-62

LaSalle JM and Lalande M (1996) Homologous association of oppositely imprinted chromosomal domains. Science 272: 725-726

Montague JW and Cidlowski JA (1996) Cellular catabolism in apoptosis: DNA degradation and endonuclease activation. Experientia 52: 957-962

Mpoke S and Wolfe J (1996) DNA digestion and chromatin condensation during nuclear death in tetrahymena. Exp. Cell Res. 225: 357-365

Oberhammer F, Wilson JW, Dive C, Morris ID, Hickman J, Wakeling AE, Walker PR, Sikorska M (1993) Apoptotic death in epithelial cells: cleavage of DNA to 300 and/ or $50 \mathrm{~kb}$ fragments prior to or in the absence of internucleosomal fragmentation. EMBO J. 12: $3679-3684$

Olive PL, Wlodek D and Banath JP (1991) DNA double-strand breaks measured in individual cells subjected to gel electrophoresis. Cancer Res. 51: 4671-4676 
Rabinovitch PS (1994) Multicycle (University of Washington). Phoenix Flow Systems Inc: San Diego, Ca. pp 2.54

Rao PN (1977) Premature chromosome condensation and the fine structure of chromosomes. In: Molecular Structure of Human Chromosomes (ed Yunis JJ). Academic Press, New York. pp 205-231

Rao PN (1990) The discovery (or rediscovery?) of the phenomenon of premature chromosome condensation. BioEssays 12: 193-197

Schwartzman RA and Cidlowski JA (1993) Apoptosis: The biochemistry and molecular biology of programmed cell death. Endocrine Rev. 14: 133-151

Sherwood SW and Schmike RT (1995) Cell cycle analysis of apoptosis using flow cytometry. In Methods in Cell Biology vol 46 (eds Schwartz LM and Osborne BA). Academic Press, San Diego, pp 77-97

Shi L, Nishioka WK, Th'ng J, Bradbury EM, Litchfield DW and Greenberg AH (1994) Premature $\mathrm{p} 34 \mathrm{cdc} 2$ activation required for apoptosis. Science 263: 1143-1145

Sigma Cell Culture Reagents (1994) In Vitro Toxicology Assay Kits. The Source 9: $1-3$

Sit KH (1996) Cell rounding with 'rip off' detachment. Histol. Histopathol. 11: 215 227

Sit KH, Bay BH, Paramanatham R, Tan HM and Wong KP (1996a) Acidification-andrecovery induces nuclear accumulation of neutral red and DNA into human KB oral carcinoma cells. Cancer Lett. 104: 63-69

Sit KH, Bay BH and Wong KP (1990) Antiport-mediated retraction: viable rounding and distinctive endocytosis. Tissue Cell 22: 785-802

SitKH, Bay BH and Wong KP (1991) Antiport-mediated rounding and endocytosis are enhanced by sulphate. Tissue Cell 23: 763-775

Sit KH, Bay BH and Wong KP (1992a) Microvillus form of focal anchorage in human Chang liver cells rounded by antiporter activation: scanning electron microscopy profiles and evidence of traction origin. Scanning Microsc. 6: 273-280

Sit KH, Bay BH and Wong KP (1992b) Distinctive uptake of neutral red by mitotic cancer cells. Biotechnic. \& Histochem. 67: 196-201

Sit KH, Bay BH and Wong KP (1993) Reduced surface area of mitotic rounding in human Chang liver cells. Anat. Rec. 235: 183-190

Sit KH, Bay BH and Wong KP (1996b) Internalization of large macromolecules in human Chang liver cells by extracellular ATP. Okaj. Folia Anat. Japan. 70: 247-
Sit KH and Chen DL (1997) Transient G2M arrest and subsequent release of apoptotic and mitotic cells in vanadyl(4)-prepulsed human Chang liver cells. Cell Death Differ. 4: 216-223

Sit KH, Paramanatham R, Bay BH and Wong KP (1994) Reduced surface area of apoptotic rounding of human Chang liver cells from serum deprivation. Anat. Rec. 246: $456-468$

Sit KH, Paramanatham R, Bay BH and Wong KP (1996c) Acidification and recovery results in nuclear accumulation of supravital dyes during interphase. Biotechnic. \& Histochem. 71: 173-181

Sundaresan M, Yu ZX, Ferrans VJ, Irani K and Finkel T (1996) Requirement for generation of $\mathrm{H}_{2} \mathrm{O}_{2}$ for platelet-derived growth factor signal transduction. Science 270: 296-299

Swe M, Bay BH and Sit KH (1996) Interphase and M-phase oral KB cells are targetted in staurosporine induced apoptosis. Cancer Lett. 104: 63-69

Telford WG, King LE and FrakerPJ (1994) Rapid quantitation of apoptosis in pure and heterogeneous cell populations using flow cytometry. J. Immunol. Meth. 72: 1-

Tounekti O, Belehradek J Jr and Mir LM (1995) Relationship between DNA fragmentation, chromatin condensation and changes in flow cytometry profiles detected during apoptosis. Exp. Cell Res. 217: 506-516

Walker PR, Weaver VM, Lach B, LeBlanc J and Skorska M (1994) Endonuclease activities associated with high molecular weight and internucleosomal DNA fragmentation in apoptosis. Exp. Cell Res. 213: 100-106

Wyllie AH, KerrJF and Currie AR (1980) Cell death: The significance of apoptosis. Int Rev. Cytol. 68: 251-300

Wyllie AH (1980) Glucocorticoid-induced thymocyte apoptosis is associated with endogenous endonuclease activation. Nature 284: 555-556

Zamai L, Falcieri E, Marhefka G, Vitale M (1996) Supravital exposure to propidium iodide identifies apoptotic cells in the absence of nucleosomal DNA fragmentation. Cytometry 23: 303-311

Zhang SZ, Lipsky MM, Trump BF and Hsu IC (1990) Neutral red (NR) assay for cell viability and xenobiotic-induced cytotoxicity in primary cultures of human and rat hepatocytes. Cell. Biol. Toxicol. 6: 219-234 